\title{
A intrusão do real no teatro dos Rimini Protokoll
}

\section{Ana Campos}

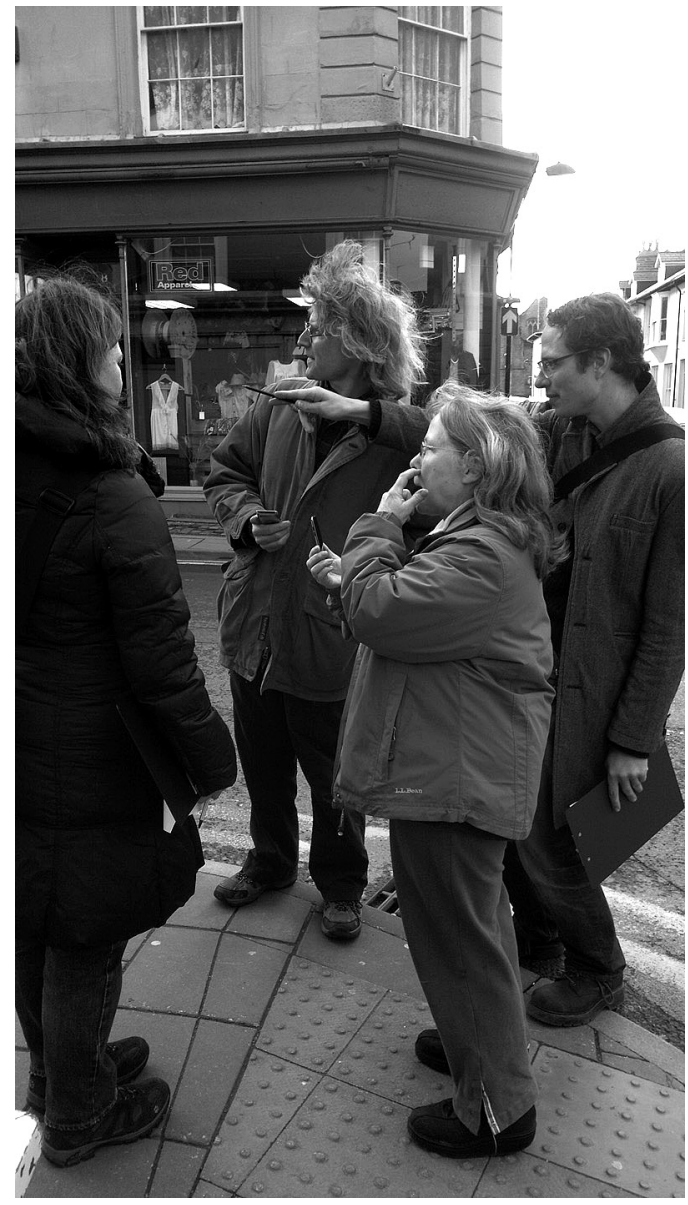

A companhia de teatro alemã, Rimini Protokoll, fundada por Helgard Haug (n. 1969), Stefan Kaegi (n. 1972) e Daniel Wetzel (n. 1969), que recentemente exibiu o seu espectáculo Remote Lisbon em Lisboa, apresenta ao público um sítio recheado de informação sobre o seu trabalho. Acessivel em www.rimini-protokoll.de, esta página, que também pode ser consultada em inglês e ainda dispõe de algumas informações noutras línguas como o português, apresenta um layoutmuito simples e de fácil utilização inversamente proporcional à quantidade imensa de informação a que por ele podemos aceder.

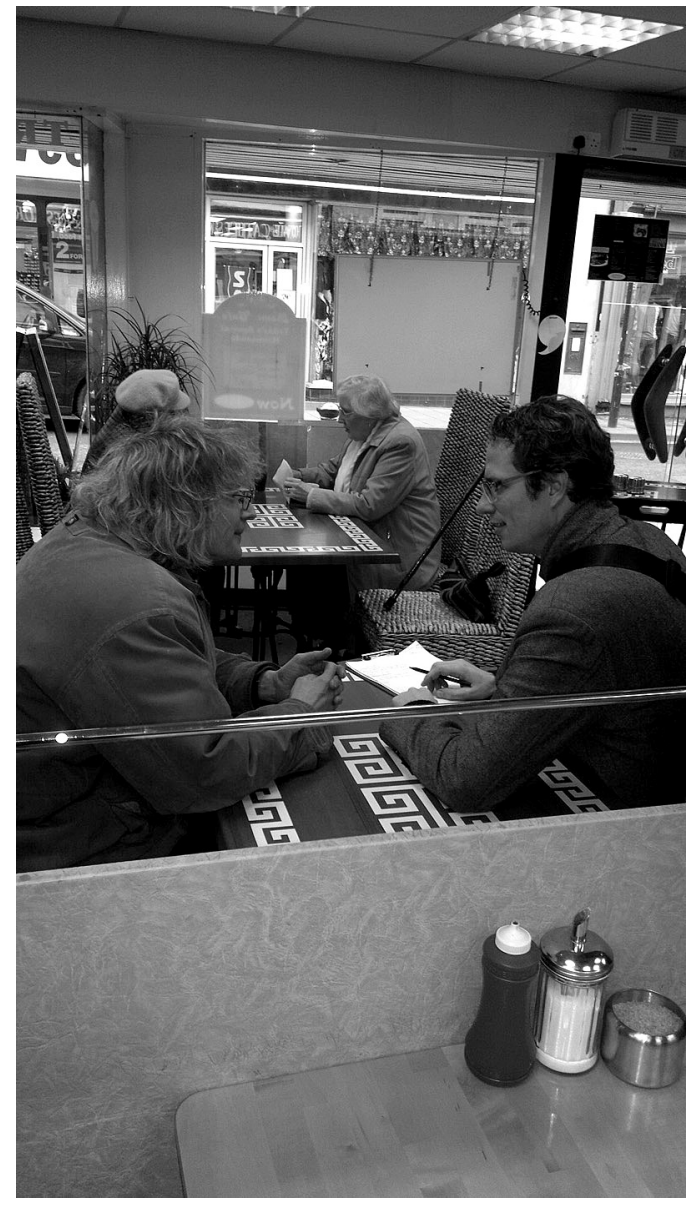

0 sítio contem informações práticas úteis, como a agenda dos espetáculos previstos e uma apresentação da companhia, como é natural neste tipo de páginas, mas o que se torna apaixonante é a quantidade de documentação sobre os espectáculos/performances que já levaram a cabo, documentação essa que vai de vídeos completos sobre as apresentações, a textos sobre as mesmas, fotografias, material diverso como os programas dos espectáculos para download, e material promocional variado.

A companhia, considerada fundadora de um novo tipo de teatro documental, procura colocar o foco da
$<>$
Outdoors

de Rimini Protokoll, em Aberystwyth 2011 (<Stefan Kaegi (dir.) dá instruçōes aos interpretes lan Rylatt e Paula Rylatt, de costas: Sarah Bickerton $>$ Stefan Kaegi (dir.) ensaia lan Rylatt) fot. Diego Barros.

Ana Campos

é doutoranda em Estudos de Teatro na Faculdade de Letras da Universidade de Lisboa e investigadora do Centro de Estudos de Teatro da mesma Faculdade. 


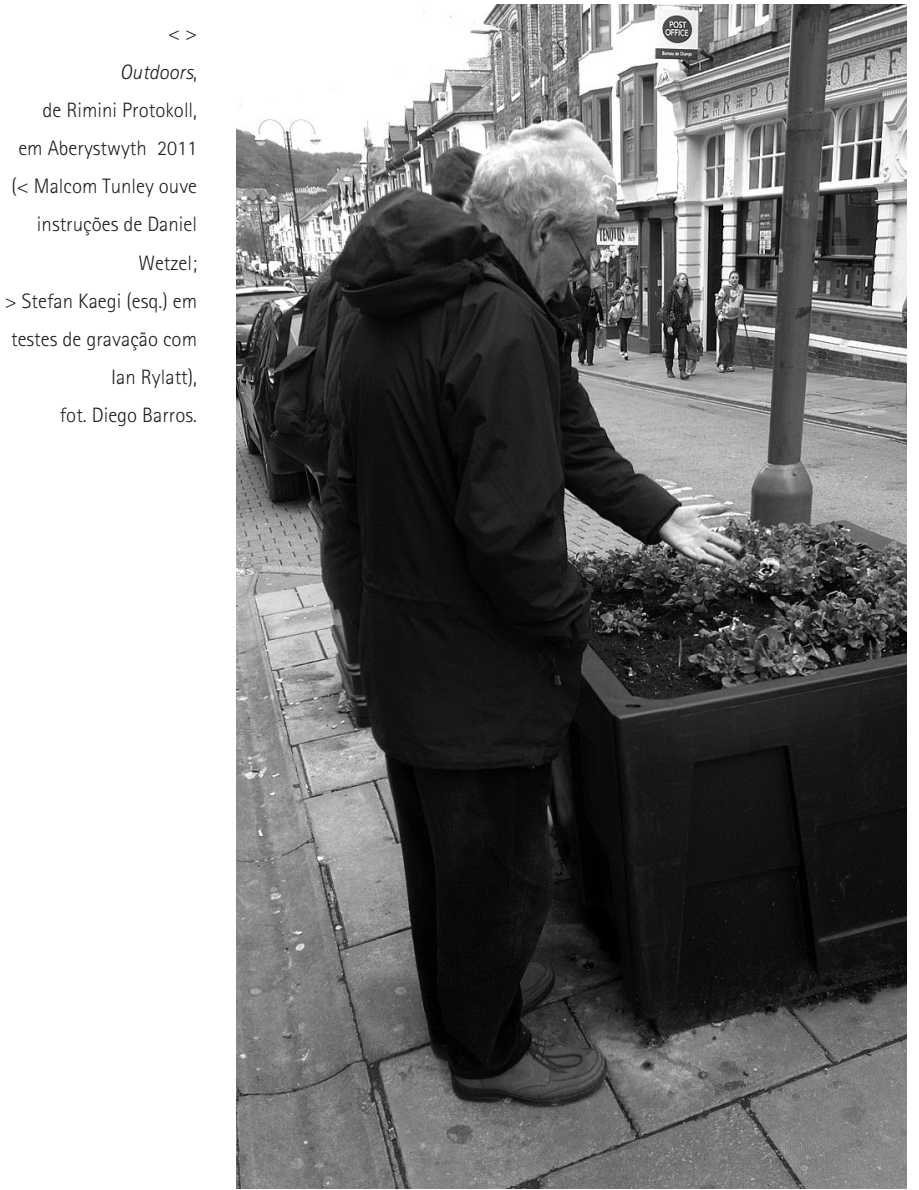

atenção do espectador em realidades com que nos cruzamos todos os dias sem reparar, porque não pertencem ao discurso oficial a que temos acesso pelos meios de comunicação, pela História oficial, pelos curricula escolares. É um teatro onde se misturam, com uma competência técnica e artística impressionantes, as novas tecnologias, diferentes tipos de texto, materiais concebidos especificamente para o projecto - como a cidade de Mnemopark - um mundo de comboio em miniatura (2007) -, a participação nos seus espectáculos de não actores ("especialistas do quotidiano", como dizem) e ainda elementos da companhia, quer sejam os performers que seja todo o staff que as produções como estas - pouco convencionais - exigem.

Muitos foram os temas que interessaram aos Rimin Protokoll: em Airport Kids, por exemplo, debruçam-se sobre as crianças da terceira cultura que vivem entre paises sem conhecerem uma zona de conforto a que possam chamar lar e com sérios problemas de definição de identidade; num outro espectáculo, a companhia colocou o enfoque sobre a vida dos camionistas búlgaros que todos os dias transportam alimentos pela Europa, sem terem eles próprios alimentos condignos para comer. Estas intervenções, contudo, não são apenas e necessariamente de cariz social. São intervenções políticas na medida em que não permitem ao espectador esquecer-se nunca de que é um cidadão da polis, sendo a polis agora o mundo inteiro, e consequentemente cabe a cada um de nós estar consciente disso mesmo nas nossas intervenções sobre ele

Interessou-me particularmente o projecto Call Cutto in a Box, que apresentaram em 2008, como reformulação

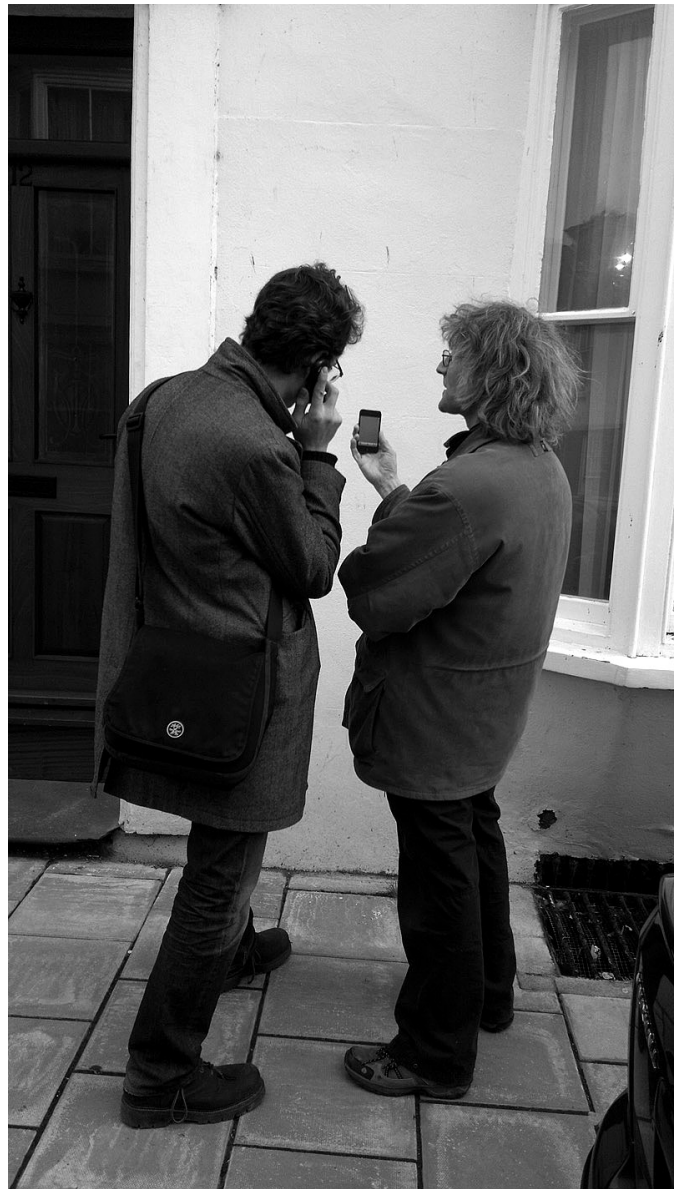

de um espectáculo anterior, cuja ideia inicial acabara por se esgotar, enquanto excelente exemplo do que o teatro relacional pode ser e dos novos caminhos que o teatro pode trilhar.

Imagine que está numa bilheteira a comprar um bilhete para um espectáculo num dia, mas não é dirigido para o auditório do espectáculo. Em vez disso, recebe uma chave de um quarto e um croqui sobre como lá chegar. Pode ser num teatro, num escritório ou num apartamento nos arredores. Quando abre a porta, toca um telefone. Atende o telefone e uma pessoa com um sotaque estranho começa a falar consigo. A pessoa parece conhecer o quarto onde você está, apesar de estar a 10.000 km de distância. A voz é a de um empregado de um call center em Calcutá. Normalmente ele e os seus colegas vendem cartões de crédito e seguros por telefone a pessoas no outro lado do mundo e ajudam as pessoas a orientar-se em cidades onde eles próprios nunca estiveram, mas aqui não é suposto comprar nada. Por agora, fica quieto e o seu interlocutor transcontinental aponta para algumas pessoas no prédio oposto. Uma história está quase a começar e descobre que você e o empregado são os protagonistas.

É mais ou menos desta forma que os Rimini Protokoll apresentam o seu projecto. 0 espectador individual assiste a um espectáculo do qual é simultaneamente 0 protagonista. Do outro lado da linha, um empregado jovial de um call center vai conduzi-lo numa cuidadosa mas avassaladora viagem para dentro de si mesmo. Depois das perguntas e respostas iniciais, muito simples, para a identificação do espectador e do actor, chamemos assim ao operador do call center, este último vai levando o seu 


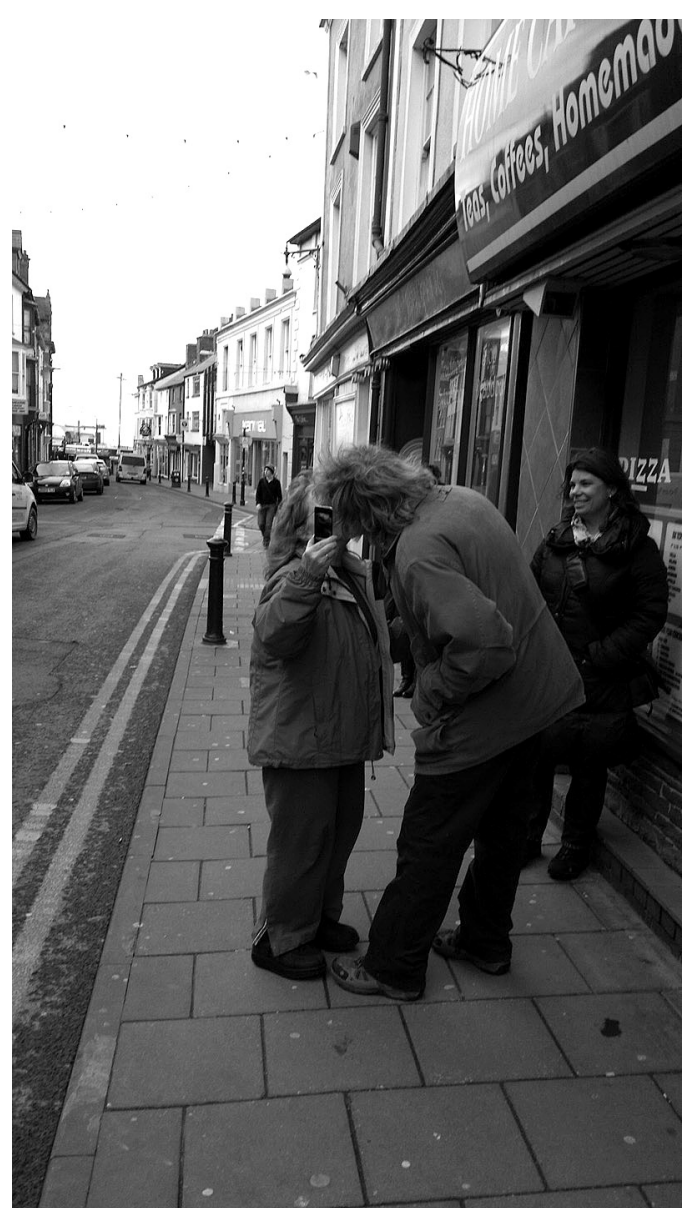

interlocutor a escavar cada vez mais fundo dentro da sua interioridade no sentido de saber o modo como se coloca perante a (sua) vida e o mundo. As perguntas sucedemse: "Está satisfeito com a sua vida?", "Acredita na reencarnação?", "Que grandes erros cometeu?" Mas, pelo meio, ocorrem momentos de grande proximidade, como aqueles em que cada um é levado a desenhar o outro sem nunca se terem visto, ou canta uma canção só para o outro ouvir, ou mesmo quando o relógio é acelerado para eliminar o fuso horário. Estabelece-se, assim, entre actor e espectador (designações pouco precisas nesta situação em que o espectador é também protagonista e o actor é espectador) uma forma de contacto entre individualidades que nunca se encontraram no mesmo lugar físico, mas que no final se sentem tão próximos que, quando termina o telefonema/contacto, o espectador parece entregue a uma extrema solidão, a solidão de quem se vê colocado perante si mesmo sem qualquer máscara social e ao mesmo tempo sabe que se expôs perante outro ser humano.

Stefan Kaegi: [...] 0 maior erro da atitude de esclarecimento é o pressuposto de que as pessoas não são emancipadas. 0 teatro não é um sanatório, mas um museu em que as coisas e as pessoas surgem retiradas de uma causalidade apressada. Para isso não são precisos nem as paredes brancas grossas do museu nem os panos pretos do teatro. 0 que importa é uma determinada concentração da atenção. 0 trabalho de encenação mais importante dá-se na cabeça do espectador, é ele próprio que o faz com o seu olhar. A mim cabeme orientar o olhar e manter o curso do pensamento - como qualquer entertainer. (Peters: 2006)
Outdoors,

de Rimini Protokoll,

em Aberystwyth 2011 (lan Rylatt e Paula Rylatt, observados por Helgard Haug), fot. Diego Barros.
Foi esta situação pessoal do espectador e a relação que ele estabelece com o operador do call center dentro de uma moldura cristalizadora que me fascinou neste espectáculo. Usando o poder comunicacional das novas tecnologias, quebrando o mito de que as relações estabelecidas virtualmente ou por telefone são menos reais, os Rimini Protokoll colocam no centro temático deste projecto a dimensão humana do espectador em toda a sua infinita complexidade e explorada em diferentes niveis de profundidade. Demonstram desta forma o lado humano, individual e único de cada pessoa, rompendo a estandartização que o aparato tecnológico é habitualmente acusado de provocar. Em última análise o espectador assiste ao espectáculo do desvendar da sua própria existência.

A propósito de Call Cutta in a Box, são inúmeras as questões que podem ser colocadas. 0 que existe de teatro aqui? Sendo teatro, quais são os papéis de cada um dos intervenientes? 0 que é significante em cena?

Penso que a dimensão teatral parte da convenção inicial: o espectador voluntária e conscientemente aceitou participar num espectáculo dentro de um espaço, que desconhecia, e aceita o pacto de ser nele conduzido pelo actor do outro lado da linha que, embora nunca tenha estado nesse tal espaço, o "conhece" perfeitamente. Para além deste aspecto formal, é importante ter em conta que os operadores de call centers levam a cabo uma representação. No seu trabalho diário, em Calcutá, na India, eles vendem produtos e orientam pessoas em viagem por lugares do mundo onde nunca estiveram, fingindo encontrar-se eles próprios noutro pais e estabelecendo 
Mnemopark

Rimini Protokoll 2007,

fot. Sebastian Hoppe.

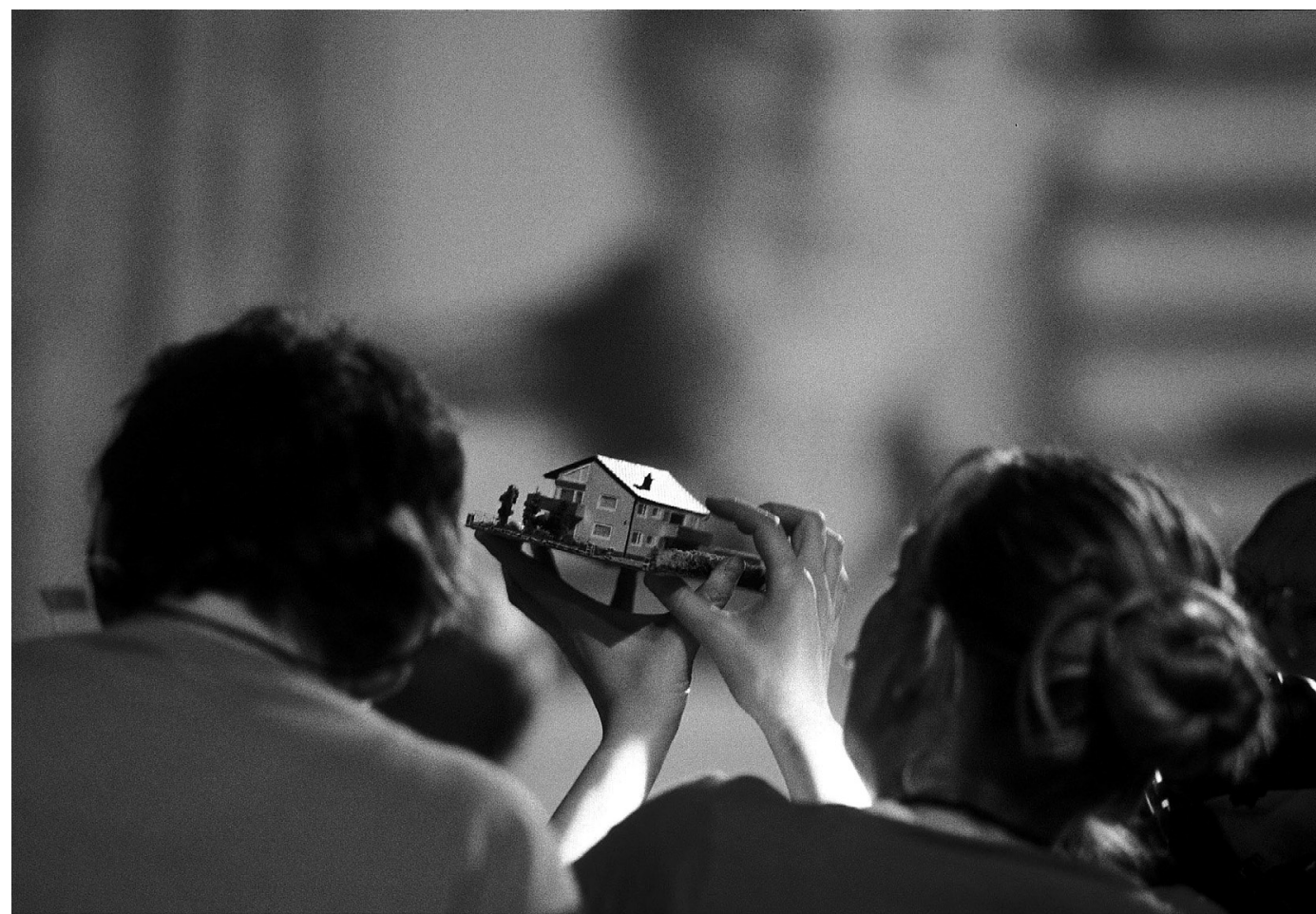

uma relação pessoal com o cliente ao ponto de, como uma das operadoras refere, nunca se despedirem para que o cliente tenha consciência de que o seu regresso é esperado. Para além disto, quando uma venda é consumada, o operador bate palmas que se estendem a todo o call center usando, assim, uma das mais clássicas convenções teatrais. Neste tipo de espectáculo, os jovens operadores usam a sua bagagem profissional para se encenarem a si próprios, pois, embora se apresentem com as suas próprias identidades e dêem dados pessoais sobre si mesmos, eles seguem um guião previamente definido que lhes permite serem eles a dirigir o espectáculo, mesmo quando, como no caso do homem que tenta convencer a sua interlocutora de que tem apenas mais um ano do que ela, o espectador tenta ser ele a tomar as rédeas do jogo.

Outro aspecto muito interessante em Call Cutta in a Box é a dimensão significante de todos os elementos em cena: o relógio que pode ser acelerado à distância para eliminar o fuso horário, a impressora que aproxima fisicamente os dois intervenientes mostrando desenhos e fotografias em tempo real, para não falar no computador no telefone, na webcam, ou mesmo no pacote de doces indianos que os espectadores/protagonistas são convidados a provar, ou a fotografia do call center que têm à sua frente. Existem ainda outros aspectos que entram na categoria dos imponderáveis, como a t-shirt usada por uma rapariga polaca com a inscrição "ser português é ser diferente" em letras brancas sobre um fundo vermelho, num momento histórico em que Portugal está sob os olhares mundiais devido à dívida à União Europeia, com todas as implicações sociais que o seu pagamento implica e numa situação em que, do outro lado da linha, o operador se encontra na Índia, destino da viagem que é hoje o exlibris do passado glorioso de Portugal.

São tudo coincidências não significantes, podem argumentar, mas a sua coincidência naquele lugar naquele tempo dentro de uma conjuntura teatral dá-Ihes uma dimensão significante de forte impacto. Assim sendo, a coluna vertebral de todo o projecto está lá, o que permite a condução por um mesmo caminho de todos os espectadores, mas também a abertura à produção de outros sentidos não previstos inicialmente, uma vez que, quem está do lado de lá da linha, espalhado por diferentes cidades da Europa, é um ser humano e, como tal, absolutamente desconhecido e imprevisivel.

0 visionamento destes espectáculos em vídeos com montagem através do sítio online cria ainda novas significações não só para os elementos em cena mas ainda para o próprio conceito de teatro aqui implícito.

\section{Referência bibliografica}

PETERS, Nina (2006), "Não um sanatório, mas um museu. Stefan Kaegi sobre o teatro como espaço de comunicação, o seu trabalho com especialistas e o sentimento de vergonha." tradução de Vera San Payo de Lemos. Theater der Zeit. Outubro.

\section{Sitiografia}

http://www.rimini-protokoll.de/website/en/index.php 